
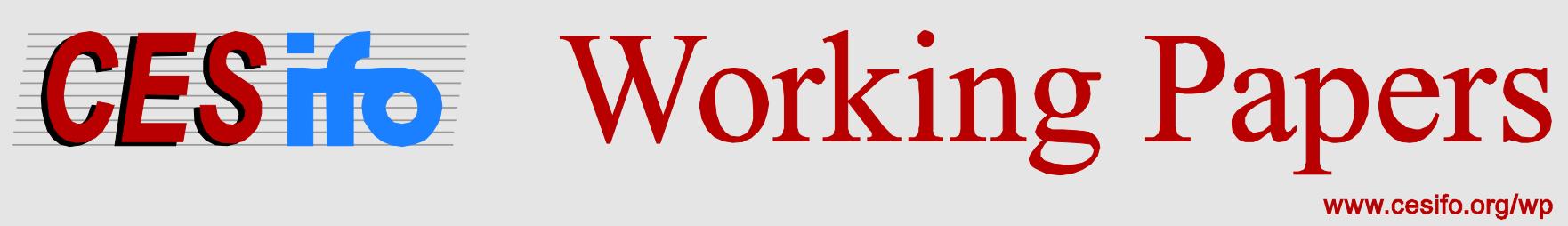

\title{
The Impact of Recent Chemotherapy Innovation on the Longevity of Myeloma Patients: U.S. and International Evidence
}

\author{
Frank Lichtenberg \\ Gisela Hostenkamp
}

\author{
CESIFO WORKING PAPER NO. 4516 \\ CATEGORY 12: EMPIRICAL AND THEORETICAL METHODS
}

DECEMBER 2013
An electronic version of the paper may be downloaded
- from the SSRN website:
- from the RePEc website:
- from the CESifo website:
WwW.SSRN.com
www.RePEc.org
www.CESifo-group.org/wp

\section{CESifo}




\title{
The Impact of Recent Chemotherapy Innovation on the Longevity of Myeloma Patients: U.S. and International Evidence
}

\begin{abstract}
There were no innovations in chemotherapy for myeloma patients during the period 19771997, but there have been several important innovations since 1997. We investigate the impact of recent chemotherapy innovation on the longevity of myeloma patients using both time-series U.S. data and longitudinal data on 26 countries.

In the US, the average annual rate of increase of life expectancy of myeloma patients at time of diagnosis was over five times as large during 1997-2005 as it had been during 1975-1997. We estimate that almost two-thirds (0.99 years) of the 1997-2005 increase in life expectancy was due to the increase in the number of chemotherapy regimens now preferred by specialists, and that the cost per U.S. life-year gained from post-1997 chemotherapy innovation did not exceed $\$ 45,551$.

We also investigate the impact of chemotherapy innovation on the myeloma mortality rate using longitudinal country-level data on 26 countries during the period 2005-2009. Countries that had larger increases in the number of chemotherapy regimens had larger subsequent declines in myeloma mortality rates, controlling for other factors. The estimates imply that chemotherapy innovation reduced the age-adjusted myeloma cancer mortality rate by about $3.1 \%$ during the period 2005-2009.
\end{abstract}

JEL-Code: I120, L650, O330.

Frank Lichtenberg

Graduate School of Business

Columbia University 3022 Broadway

USA - 10027 New York NY

frank.lichtenberg@columbia.edu
Gisela Hostenkamp

COHERE / Department of Business and Economics University of Southern Denmark Campusvej 55

Denmark - 5230, Odense M gih@sam.sdu.dk 


\section{Introduction}

Multiple myeloma is a type of bone marrow cancer, where plasma cells found in the bone marrow divide uncontrollably and form tumors that can destroy bones and damage the kidneys (Harrison, 2013). The incidence varies globally from 1 per 100000 people in China, to about 4 per 100000 in most developed countries. It is the second most frequent malignancy of the blood in the USA, where about 20000 new cases occur every year in the USA. Median age at diagnosis is reported to lie between 61 and 70 years of age and only $2 \%$ of patients are younger than 40 years (Cook, 2008, Raab et al., 2009)

Two reliable sources indicate that, between 1977 and 1997, there were no innovations in chemotherapy ${ }^{1}$ for myeloma patients, but that there have been numerous innovations since 1997. The first source is the National Cancer Institute (NCI) Thesaurus database. ${ }^{2}$ The NCI Thesaurus (NCIt) identifies chemotherapy regimens currently used to treat plasma cell myeloma. ${ }^{3}$ It also identifies the components (drugs) included in each regimen. For example, one of the regimens used to treat plasma cell myeloma is the "lenalidomide-dexamethasone regimen," which has three components: dexamethasone, bortezomib, and lenalidomide. ${ }^{4}$ These three drugs were approved by the FDA in 1958, 2003, and 2005, respectively. ${ }^{5}$ Therefore, 2005 is the first year in which an American myeloma patient could have been treated with the "lenalidomidedexamethasone regimen." Table 1 shows the regimens used to treat plasma cell myeloma, as defined in the NCI Thesaurus, the drugs included in each regimen, the FDA approval year of those drugs, and the "regimen year": the FDA approval year of the most recently approved drug included in the regimen.

\section{Table 1 about here}

\footnotetext{
${ }^{1}$ Chemotherapy is defined as the treatment of cancer using specific chemical agents or drugs that are selectively destructive to malignant cells and tissues.

${ }^{2}$ The National Cancer Institute Thesaurus (NCIt: http://ncit.nci.nih.gov) provides reference terminology for many NCI and other systems. It covers vocabulary for clinical care, translational and basic research, and public information and administrative activities.

${ }^{3}$ Appendix 1 shows NCIt's list of Chemotherapy Regimen used to Treat Plasma Cell Myeloma (Code C63496) http://ncit.nci.nih.gov/ncitbrowser/pages/concept details.jsf?dictionary=NCI\%20Thesaurus\&version=12.10e\&code $=$ C63496\&type $=$ relationship accessed 20/12/2012.

${ }^{4} \mathrm{NCIt}$ 's list of substances included in drug regimen lenalidomide-dexamethasone http://ncit.nci.nih.gov/ncitbrowser/pages/concept details.jsf?dictionary=NCI\%20Thesaurus\&version=12.10e\&code $=$ C64732\&type $=$ relationship accessed 20/12/2012

${ }^{5}$ Based on Drugs@FDA Data Files, http://www.fda.gov/Drugs/InformationOnDrugs/ucm079750.htm accessed $17 / 12 / 2012$
} 
Six of the twelve regimens currently used to treat plasma cell myeloma could have been used by 1977 . No new regimens were added during the next 20 years. ${ }^{6}$ Due to the approval of three new drugs (thalidomide, bortezomib, and lenalidomide), the number of available regimens doubled (from six to twelve) between 1997 and 2005. Thalidomide was the first-in-class immunomodulatory agent with an indication for multiple myeloma patients. Thalidomide and lenalidomide target both multiple myeloma cells and the bone marrow microenvironment (Raab et al., 2009), whereas bortezomib is a chemotherapeutic agent that induces cancer cell death by inhibiting the proteasome enzyme complex involved in cell cycle control and growth (Harrison, 2013). These agents target the immune system in such a way that patients suffers minimum damage and normal function of the immune system remains intact (Kumar and Chhibber, 2011).

The second source is The Elsevier Guide to Oncology Drugs and Regimens (2012 edition) (also known as OncologySTAT)(Elsevier, 2012). OncologySTAT provides a comprehensive list of more than 290 commonly used single-agent and combination regimens used in the treatment of 26 cancer types. The regimens listed are those most widely used and are in accordance with guideline recommendations of the National Comprehensive Cancer Network, American Society of Clinical Oncology, and National Cancer Institute. They were selected by oncologists at major U.S. cancer centers, including members of the OncologySTAT Advisory Board. Table 2 shows the regimens used to treat multiple myeloma, as defined in OncologySTAT, the drugs included in each regimen, the FDA approval year of those drugs, and the "regimen year"?

The NCIt and OncologySTAT lists of myeloma chemotherapy regimens differ in some respects. The NCIt list includes twice as many "old" (pre-1998) regimens as the OncologySTAT list: six as opposed to three. OncologySTAT also distinguishes between regimens designated by specialists as preferred for use in clinical practice and regimens that are not preferred. As shown in Table 2, half of the regimens are preferred regimens, and all of these are "new" (post-1997) regimens.

\section{Table 2 about here}

\footnotetext{
${ }^{6}$ Stem cell transplantation was introduced for the treatment of myeloma in the 1980 s, but patients must be fairly young and healthy to withstand the side-effects of transplantation. Many myeloma patients therefore do not qualify for transplantation. Ramesh (2013) reports that only about $5 \%$ of myeloma patients received stem-cell transplantations in 1994 and according to HCUPnet, only 3963 bone marrow transplants were performed on multiple myeloma patients in $2011 \mathrm{http://hcupnet.ahrq.gov/HCUPnet.jsp}$

7 Appendix 2 shows OncologySTAT's list of chemotherapy regimens used to treat multiple myeloma http://oncologystat.com/drugs_and_regimens/chemo_regimens/multiple_myeloma.html
} 
Although there are some discrepancies, both sources indicate that there were no innovations in chemotherapy for myeloma patients during the period 1977-1997, but that there have been numerous innovations since 1997. This is illustrated in Figure 1, which shows annual data on the number of NCIt regimens, OncologySTAT regimens, and preferred OncologySTAT regimens that could have been used to treat American myeloma patients during the period 19772012 .

In this paper, we will investigate the impact of chemotherapy innovation on the survival of myeloma patients using two different approaches. First, we will investigate this impact using annual U.S. time-series data during the period 1975-2009. We believe that the sharp discontinuity in the number of available chemotherapy regimens enables us to identify this impact. $^{8}$ Second, we will investigate this impact using longitudinal country-level data on 26 countries during the period 2005-2009. In this case, identification is enabled by the fact that some chemotherapy regimens became available later in some countries than in others, or did not become available in some countries by the end of 2010 .

In both approaches, the treatment variable is the (current or lagged) number of chemotherapy regimens that could have been used to treat myeloma patients (which, as described above, can be measured in several different ways). This is not an ideal treatment measure: We would prefer to have data on the number of patients actually treated with each regimen. Unfortunately, data on the number of myeloma patients treated, by chemotherapy regimen and year (and country), are not available. However, there is likely to be a significant correlation between the number of available treatments and the distribution of actual treatments. If a treatment is not available, the number of patients receiving that treatment is certainly zero. Lichtenberg (2013) has shown that when the number of drugs in a drug class increases, the mean vintage (FDA approval year) of drugs consumed increases.

In the next section we will review the related literature. In section 3 we will analyze the impact of chemotherapy innovation on myeloma survival and mortality using annual U.S. timeseries data during the period 1975-2009. In section 4 we will analyze this impact using longitudinal country-level data on 26 countries during the period 2005-2009. Section 5 provides a summary and conclusions.

\footnotetext{
${ }^{8}$ Lichtenberg (2006) exploited the sharp discontinuity in HIV drug innovation to investigate the impact of new drugs on the longevity of HIV/AIDS patients.
} 


\section{Related Literature}

There are numerous randomized clinical trials (RCTs) demonstrating the efficacy of thalidomide, lenalidomide and bortezomib in the treatment of multiple myeloma. These studies provide convincing evidence on clinical efficacy for the three new agents -showing a health benefit over a placebo or other standard of care intervention when tested in an ideal situation (Thaul, 2012). Raab et al. (2009) provide a very good overview of the clinical studies involving one or more of the advanced agents up to 2009. The evidence from these RCTs documents that all three advanced agents are effective treatments for multiple myeloma (MM) in combination with standard treatment therapy and stem-cell transplantations, both in newly diagnosed patients and in relapsed and refractory MM. However, advanced agents administered alone show only small improvements over standard treatment therapy (Barlogie et al., 2001).

In recent years clinical research has concentrated on finding the optimal substance dose combinations and sequencing tailored to the patient's characteristics such as age and risk factors, to avoid drug resistance (Baz et al., 2013). However, to the best of our knowledge there have not yet been any direct, "head-to-head" studies comparing the effectiveness of the three novel agents against each other in clinical practice (Kumar et al., 2011).

Partly owing to the relatively short follow-up times, only a few RCTs report outcomes in terms of overall survival (Facon et al., 2007, Hulin 2007). Although not all RCTs demonstrate significant improvements in this dimension (Palumbo et al., 2006), patients receiving advanced treatment are more likely to experience at least partial response to treatment and longer time to disease progression and (adverse) event free survival (Harousseau et al., 2007). RCTs have the disadvantage that they often observe patients only while on a specific treatment and not before or afterwards. In addition, the patient population in clinical trials is often highly selective and may not represent the patient population in clinical practice,

In contrast, the current study provides evidence on the three new agents' effectiveness in real-life situations, where patients are not highly selected and represent greater regional diversity. Using a time series of aggregate cancer survival statistics and changes in the availability of advanced therapy combinations we can include all patients, including those who switch between treatments during the observation period. In addition, since we have relatively long follow-up 
times (at least for U.S. patients), we can measure outcomes in terms of overall survival and can calculate overall cost effectiveness (cost per life year gained), which is a criterion used in HTA and in many health insurance coverage decisions. The current study therefore provides evidence on the combined effectiveness of a new generation of agents comprised of two classes of medicines that affect the bone marrow environment of tumor cells through two different modes of action, rather than comparing the three agents' effectiveness against each other.

\section{Chemotherapy innovation and myeloma survival in the U.S., 1975-2005}

We will analyze the impact of chemotherapy innovation on two different measures of myeloma survival or mortality. The first measure is the 5-year relative survival rate. Relative survival was developed to provide an objective measure of the probability of survival of cancer in the absence of other causes of death (Ederer et al., 1961). It is a measure that is not influenced by changes in mortality from other causes and, therefore, provides a useful measure for tracking survival across time. Relative survival compares the observed survival proportion of a group of cancer patients with the survival of a "similar" theoretical cancer-free group. Relative survival is formally defined as the ratio of the observed survival (all causes of death) of a cohort of cancer patients to the expected survival of a comparable set of cancer-free individuals .

Data on the 5-year relative survival rate in the years 1977,1997 , and $2005^{9}$ are 24,7 , $32,3 \%$ and $40,9 \%$ respectively, which means that the average annual change in survival rate increased almost three times as rapidly during the period 1997-2005 compared to 1977-1997 (Howlader et al., 2012).

We will estimate models of the 5 -year relative survival rate of the following form: ${ }^{10}$

$$
\text { rel_surv }{ }_{\mathrm{t}}=\alpha+\beta \mathrm{n}_{-} \text {regimen } \mathrm{t}+\gamma \mathrm{t}+\varepsilon_{\mathrm{t}}
$$

where

rel_surv $\mathrm{t}_{\mathrm{t}}=$ the 5-year relative survival rate of patients diagnosed with myeloma in year $\mathrm{t}(\mathrm{t}=$ $1975, \ldots, 2005)$

$\mathrm{n} \_$regimen $_{\mathrm{t}}=$ the number of myeloma chemotherapy regimens that could have been used to

\footnotetext{
${ }^{9}$ Source: Authors calculations based on SEER Program (www.seer.cancer.gov) 1975-2009 using SEER*Stat 8.0.1. statistical software package (released 2012). 2005 is the most recent year for which data on the 5-year relative survival rate were available at the time of the analysis.

${ }^{10} \mathrm{We}$ will allow for first-order serial correlation of residuals in all models described in this section.
} 
treat myeloma patients in year $\mathrm{t}$

By including the time trend $(\mathrm{t})$ as a regressor, we control for the general tendency of rel_surv to rise throughout the sample period. Since rel_surv is "forward-looking" (rel_surv $\mathrm{t}_{\mathrm{t}}$ depends on conditional mortality rates in years $\mathrm{t}, \mathrm{t}+1, \mathrm{t}+2, \mathrm{t}+3$, and $\mathrm{t}+4$ ), this model implicitly incorporates a lag between the introduction of new chemotherapy regimens and conditional mortality rates. A lag is probably appropriate since new chemotherapy regimens are likely to diffuse gradually. We will estimate eq. (1) using several alternative definitions of n_regimen: the number of NCIt regimens (NCIt_reg ${ }_{t}$ ), the number of OncologySTAT regimens (OncSTAT_reg $)$, and the number of preferred and non-preferred OncologySTAT regimens (OncSTAT_pref $f_{t}$ and OncSTAT_nonpref $f_{\mathrm{t}}$ respectively).

The second dependent variable (survival measure) we will analyze is life expectancy at time of myeloma diagnosis. We construct this measure using patient-level data on people diagnosed with myeloma from SEER 9 registries $^{11}$ during the period 1973-2005. Each record in the 1973-2009 SEER research database indicates (1) the patient's date of diagnosis; (2) the Survival Time Recode, calculated using the date of diagnosis and one of the following: date of death, date last known to be alive, or follow-up cutoff date (December 31, 2009); and (3) vital status at cutoff date (1: Alive; 4: Dead). To obtain valid estimates of life expectancy (time till death) at time of diagnosis, it is necessary to account for the fact that the survival time data are right-censored (some patients were still alive on the follow-up cutoff date). We do this by estimating models of survival time using a statistical procedure (the SAS LIFEREG procedure) that fits parametric models to failure time data that can be right censored. ${ }^{12}$ We will assume that the number of years the patient lived after being diagnosed (or the number of years till death) has the Weibull distribution, one of the most commonly used distributions in failure time analysis. The probability density function of a Weibull random variable $\mathrm{x}$ is:

$$
\begin{aligned}
\mathrm{f}(\mathrm{x} ; \lambda, \mathrm{k}) & =(\mathrm{k} / \lambda)(\mathrm{x} / \lambda)^{\mathrm{k}-1} \exp \left(-(\mathrm{x} / \lambda)^{\mathrm{k}}\right) & & \mathrm{x} \geq 0 \\
& =0 & & \mathrm{x}<0
\end{aligned}
$$

\footnotetext{
${ }^{11}$ The SEER 9 registries are Atlanta, Connecticut, Detroit, Hawaii, Iowa, New Mexico, San Francisco-Oakland, Seattle-Puget Sound, and Utah. Data are available for cases diagnosed from 1973 and later for these registries with the exception of Seattle-Puget Sound and Atlanta. The Seattle-Puget Sound and Atlanta registries joined the SEER program in 1974 and 1975, respectively.

${ }^{12}$ Lichtenberg (2013a), (Lichtenberg, 2013b) used this approach to estimate the effect of pharmaceutical innovation on the longevity of elderly Americans and to estimate the effect of hospital procedure innovation on the longevity of residents of Western Australia.
} 
where $k>0$ is the shape parameter and $\lambda>0$ is the scale parameter of the distribution. ${ }^{13}$ The mean of a Weibull random variable can be expressed as $\lambda \Gamma(1+(1 / \mathrm{k}))$ where $\Gamma(\mathrm{z})$ is the Gamma function(Kleinbaum and Mitchel, 2012):

$$
\Gamma(z)=\int_{0}^{\infty} t^{z-1} e^{-t} d t
$$

Estimates of the Weibull distribution parameters and related statistics, by year of myeloma diagnosis, are shown in Table 3.

Table 3 about here

Estimates of life expectancy (the mean of the Weibull distribution), by year of diagnosis, are shown in Figure 2.

Figure 2 about here

Between 1975 and 1997, life expectancy increased by 0.77 years, from 3.38 to 4.15 years. Between 1997 and 2005, life expectancy increased by 1.53 years, from 4.15 to 5.68 years. The increase in life expectancy during 1997-2005 was double the increase in life expectancy during the previous 22 years; the average annual rate of increase was over five times as large during 1997-2005 as it had been during 1975-1997. Our estimates of life expectancy are broadly consistent with evidence obtained from clinical studies: "With conventional treatment, median survival is 3-4 years, which may be extended to 5-7 years or longer with advanced treatments.”(Raab et al., 2009)

We will analyze the impact of chemotherapy innovation on life expectancy at time of myeloma diagnosis by estimating equations of the following form:

$$
\text { le_diag }{ }_{t}=\alpha+\beta \text { n_regimen } n_{t}+\gamma t+\varepsilon_{t}
$$

where

le_diag $\operatorname{dife}_{\mathrm{t}}=$ life expectancy (mean time till death) of patients diagnosed with myeloma in year

$$
\mathrm{t}(\mathrm{t}=1975, \ldots, 2005)
$$

All of the 1975-2009 U.S. time-series data on myeloma that we will use to estimate eqs. (1)-(3) are shown in Table 4.

Table 4 about here

\footnotetext{
${ }^{13}$ The Weibull distribution offers a flexible way to model a wide variety of data. If $\mathrm{k}=1$, the Weibull distribution is identical to the exponential distribution; if $k<1$ the Weibull has a decreasing hazard function; if $k=2$, the Weibull distribution is identical to the Rayleigh distribution and if $\mathrm{k}$ is between 3 and 4 the Weibull distribution approximates the normal distribution.
} 
Estimates of models of the 5-year relative survival rate and of life expectancy at time of diagnosis (eqs. (1) and (2)) are presented in Table 5.

Table 5 about here

The dependent variable in models 1-4 is the 5-year relative survival rate. Model 1 includes the number of NCI Thesaurus regimens (NCIt_reg) and a time trend (Year). The NCIt_reg coefficient is positive and significant $(\mathrm{p}$-value $=.0398)$, indicating that the 5 -year relative survival rate increased more rapidly during years when the number of NCI Thesaurus regimens increased more rapidly. Between 1997 and 2005, the number of NCI Thesaurus regimens increased from 6 to 12. The estimated NCIt_reg coefficient implies that this increased the survival rate by 4.5 percentage points $(.0075 * 6=$ $.045)$. This is slightly more than half of the actual 8.5 percentage point increase in the survival rate (from $32.3 \%$ to $40.8 \%$ ).

In model 2, we replace the number of NCI Thesaurus regimens by the number of OncologySTAT regimens (OncSTAT_reg). The OncSTAT_reg coefficient is more significant $(\mathrm{p}$-value $=.0103)$ than the NCIt_reg coefficient and has a similar magnitude. Between 1997 and 2005, the number of OncologySTAT regimens increased from 3 to 10. The estimated OncSTAT_reg coefficient implies that this increased the survival rate by 5.0 percentage points $(.0072 * 7=.050)$.

In model 3, we replace the total number of OncologySTAT regimens by the number of “preferred” (by specialists) OncologySTAT regimens (OncSTAT_pref). The OncSTAT_pref coefficient is much larger and more significant $(\mathrm{p}$-value $=.0008)$ than the NCIt_reg and OncSTAT_reg coefficients. Evidently, the introduction of a preferred regimen has a much greater impact on the survival rate than the introduction of a non-preferred regimen. Between 1997 and 2005, the number of preferred OncologySTAT regimens increased from 0 to 5 . The estimated OncSTAT_pref coefficient implies that this increased the survival rate by 6.4 percentage points $(.0128 * 5=.064)$. The increase in the number of preferred OncologySTAT regimens explains $75 \%$ of the 8.5 percentage point increase in the survival rate during 1997 2005.

Model 4 includes the number of "non-preferred" OncologySTAT regimens (OncSTAT_nonpref =OncSTAT_reg - OncSTAT_pref) as well as the number of "preferred" 
OncologySTAT regimens. The coefficient on OncSTAT_nonpref is not statistically significant, indicating that the introduction of a non-preferred regimen has no impact on the survival rate.

Models 5-8 are similar to models 1-4, but the dependent variable in models 5-8 is life expectancy at time of diagnosis. The coefficients on NCIt_reg, OncSTAT_reg, and OncSTAT_pref are all positive and highly significant. Between 1997 and 2005, life expectancy at time of diagnosis increased by 1.53 years, from 4.15 to 5.68 years. Model 5 implies that about half $(.1245 * 6=0.747$ years $)$ of the increase in life expectancy was due to the increase in the number of NCI Thesaurus regimens. Similarly, model 6 implies that about half $(.1082 * 7=$ 0.757 years) of the increase in life expectancy was due to the increase in the total number of OncologySTAT regimens. Model 7 implies that about almost two-thirds $(.1971 * 5=0.986$ years) of the increase in life expectancy was due to the increase in the number of "preferred" OncologySTAT regimens. Model 8 includes the number of "non-preferred" OncologySTAT regimens as well as the number of "preferred" OncologySTAT regimens. The coefficient on OncSTAT_nonpref is negative and significant, suggesting that, controlling for the number of preferred regimens, an increase in the number of non-preferred regimens reduces life expectancy. ${ }^{14}$ However, the detrended values of OncSTAT_pref and OncSTAT_nonpref are very highly correlated, ${ }^{15}$ so distinguishing between the effects of preferred and non-preferred regimens on life expectancy is difficult. Controlling for OncSTAT_nonpref increases the coefficient on OncSTAT_pref by 61\% (from 0.197 to 0.317 ). Model 8 implies that the net effect of increases in the number of preferred and non-preferred regimens during 1997-2005 was to increase life expectancy by 1.13 years $(0.317 * 5-0.226 * 2=1.13)$.

\section{Chemotherapy innovation and myeloma mortality in 26 countries, 2005-2009}

Now we will analyze the impact of chemotherapy innovation on myeloma mortality using longitudinal annual data on 26 countries during the period 2005-2009. Data on age-adjusted myeloma mortality rates, by country and year, where obtained from the World Health Organization

\footnotetext{
${ }^{14}$ It is possible that when the number of non-preferred regimens increases and the number of preferred regimens remains constant, the probability that a patient will be treated with a non-preferred regimen increases, which could reduce survival.

${ }^{15}$ The correlation between the residuals from the regressions of OncSTAT_pref and OncSTAT_nonpref on the time trend is 0.69 (p-value $<.0001)$.
} 
Cancer Mortality Database(World Health Organization Cancer Mortality Database). The chemotherapy measures will be similar to the ones used in the U.S. time-series analysis:

NCIt_reg ${ }_{\mathrm{ct}}=$ the number of NCI Thesaurus regimens that could have been used in country $\mathrm{c}$ in year $\mathrm{t}$

OncSTAT_reg ct $_{\text {in }}=$ the total number of OncologySTAT regimens that could have been used in country $\mathrm{c}$ in year $\mathrm{t}$

OncSTAT_pref $f_{\mathrm{ct}}=$ the number of "preferred" OncologySTAT regimens that could have been used in country $\mathrm{c}$ in year $\mathrm{t}$

OncSTAT_nonpref $f_{\mathrm{ct}}=$ the number of "nonpreferred" OncologySTAT regimens that could have been used in country $\mathrm{c}$ in year $\mathrm{t}$

Construction of these variables requires information about whether each of the drugs listed in Tables 1 and 2 were available in each country and year. This information was obtained from a database provided by IMS Health, which included annual data on drug sales by molecule, country, and year during the period 1999-2010. This database allowed us to determine the earliest year (starting in 1999) that each drug listed in Tables 1 and 2 was sold in each country.

Table 6 about here

Table 6 shows the first post-1998 year in which each drug was sold in each country. A blank cell indicates that the drug was not sold in that country by the end of 2010, and an entry of 1999 can indicate that the drug could have been available even before 1999. Lenalidomide was not available in more than half of the countries by the end of 2010.

Unfortunately, the U.S. is the only country for which it is possible to calculate life expectancy at time of diagnosis. Also, data on the relative survival of myeloma patients, by country and year, are generally not available for most countries and years, especially recent years. One exception is Australia, which publishes data on the 5-year relative survival rate from myeloma for five time periods, from 1982-1987 to 2006-2010. Those data are shown in Figure 3. 16

\footnotetext{
${ }^{16}$ Relative survival in Australia was calculated using the period method by Brenner and Gefeller (1996). The period method calculates survival from a given follow-up or at-risk time period. Survival estimates are based on the survival experience of people who were diagnosed before or during this period, and who were at risk of dying during this period. Because the period method allows recent years of follow-up to be selected, it produces up-todate survival estimates that reflect recent changes in cancer survival trends (Brenner and Hakulinen, 2002). The period method is an alternative to the traditional cohort method, which focuses on a group of people diagnosed with cancer in a past time period, and follows these people over time.
} 
Figure 3 about here

Figure 3 bears a strong resemblance to Figure 2, which shows the life expectancy at time of diagnosis of American myeloma patients. The relative survival of Australian myeloma patients grew much more rapidly after 1999 than it had before then.

Given the paucity of international data on the relative survival and life expectancy of myeloma patients, we will analyze an alternative outcome measure: the age-adjusted myeloma mortality rate, i.e. the number of deaths whose underlying cause was myeloma per 100,000 population. ${ }^{17}$ Unlike the previous two measures, this measure is not conditional upon a diagnosis of myeloma, nor does it depend on the number of people diagnosed with myeloma. Some analysts argue that not conditioning on diagnosis is desirable, since patterns of diagnosis may change over time, which could distort measures that condition on diagnosis. In particular, earlier diagnosis could introduce lead-time bias ${ }^{18}$ into measures like relative survival and life expectancy at time of diagnosis. ${ }^{19}$ However, if the true incidence of a disease is increasing, the age-adjusted mortality rate from the disease may rise even if there is progress in treating the disease. Longitudinal country-level data on myeloma incidence are rather incomplete, ${ }^{20}$ so we are unable to control for incidence. But it seems likely that countries with higher incidence growth would be more likely to adopt chemotherapy innovations (and to have higher mortality growth), so failure to control for incidence is likely to cause estimates of the effect of chemotherapy innovation on mortality to be conservative.

We will analyze the impact of chemotherapy innovation on the age-adjusted myeloma mortality rate ${ }^{21}$ by estimating equations of the following form:

$$
\ln \left(\text { mort_rate }_{\mathrm{ct}}\right)=\beta \text { n_regimen }_{\mathrm{c}, \mathrm{t}-2}+\pi \mathrm{Z}_{\mathrm{ct}}+\alpha_{\mathrm{c}}+\delta_{\mathrm{t}}+\varepsilon_{\mathrm{ct}}
$$

where

\footnotetext{
${ }^{17}$ A reduction in the annual mortality rate (the probability of dying in a given year) would increase life expectancy. If the probability distribution of life expectancy (time till death) were exponential, and the rate parameter (death rate) were $\lambda$, mean time till death is $1 / \lambda$.

${ }^{18}$ See http://medical-dictionary.thefreedictionary.com/lead-time+bias

${ }^{19}$ Using data from the U.S. and Australia, Lichtenberg (2010) showed that, while the change in the 5-year survival rate is not a perfect measure of progress against cancer, in part because it is potentially subject to lead-time bias, it does contain useful information; especially for diseases for which development of early detection methods have been limited. According to www.cancer.org it is still difficult to diagnose MM early since symptoms often first appear when the disease reaches an advanced stage http:/www.cancer.org/cancer/multiplemyeloma/detailedguide/multiple-myeloma-detection.

${ }^{20}$ The GLOBOCAN project provides data on the incidence of myeloma in 184 countries, but only for a single year (2008) http://globocan.iarc.fr/.

${ }^{21}$ Data on other country attributes were obtained from the World Bank.
} 
mort_rate ${ }_{\mathrm{ct}}=$ the age-adjusted myeloma mortality rate in country $\mathrm{c}$ in year $\mathrm{t}(\mathrm{t}=$ $2005, \ldots, 2009)$

n_regimen $_{\mathrm{c}, \mathrm{t}-2}=$ the number of chemotherapy regimens that could have been used to treat myeloma patients in country $\mathrm{c}$ in year $\mathrm{t}-2$

$\mathrm{Z}_{\mathrm{ct}}=$ other attributes of country $\mathrm{c}$ in year $\mathrm{t}$ : the log of real per capital GDP, the log of real per capital health expenditure, the unemployment rate, and the fraction of the population residing in urban area

$\alpha_{c}=$ a fixed effect for country $\mathrm{c}$

$\delta_{\mathrm{t}}=\mathrm{a}$ fixed effect for year $\mathrm{t}$

Since it includes fixed country and year effects, eq. (3) is a difference-in-differences model. A significant negative estimate of $\beta$ would indicate that countries with larger increases in the lagged number of myeloma chemotherapy regimens had larger declines (or smaller increases) in myeloma mortality. As noted earlier, relative survival and life expectancy at time of diagnosis are "forward looking," but the age-adjusted mortality rate is not, so we allow for a 2-year lag in the relationship between chemotherapy innovation and mortality: mort rate ${ }_{t}$ depends on $\mathrm{n} \_$regimen $_{\mathrm{t}-2}$. We will estimate eq. (3) using weighted least-squares, weighting by the population of country c in year $\mathrm{t}$. We will also allow for clustering of standard errors within countries.

Table 7 about here

Estimates of eq. (3) are presented in Table 7. In the first model (model 9), the chemotherapy variable is the number of NCI Thesaurus regimens in year t-2 (NCIt_reg $\mathrm{c}, \mathrm{t}-\mathrm{2}_{2}$ ), and no other time-varying attributes of country $\mathrm{c}$ are included $\left(\mathrm{Z}_{\mathrm{ct}}\right.$ is excluded). The coefficient on NCIt_reg ${ }_{c, t-2}$ is negative and significant ( $p$-value $=0.0345$ ), which indicates that countries that had larger increases in the number of NCI Thesaurus regimens had larger subsequent declines in myeloma mortality rates. Between 2005 and 2009, the (population-weighted) mean value of NCIt_reg ${ }_{c, t-2}$ increased by 1.90 , so the estimate implies that chemotherapy innovation reduced the age-adjusted mortality rate by about $3.1 \%$ during this period $(-.0162 * 1.90=-.031)$.

The same chemotherapy variable is included in model 10 , but that model also includes the other time-varying country attributes described above. To conserve space, we do not report complete estimates of the coefficients of these attributes. But it is worth pointing out that in this model and models 12, 14, and 16, the coefficient of the GDP variable is positive and highly 
significant, ${ }^{22}$ the coefficient of the health expenditure variable is negative and highly significant, and the coefficients of the unemployment and urbanization rates are far from statistically significant. However, controlling for these other factors has virtually no effect on the coefficient of the chemotherapy variable.

Models 11-12 are similar to models 9-10, but the lagged number of NCI Thesaurus regimens is replaced by the lagged number of OncologySTAT regimens (OncSTAT_reg $\mathrm{c}_{\mathrm{c}, \mathrm{t}-2}$ ). The coefficients in models 11-12 are very similar to the coefficients in models 9-10.

In models 13-14, the chemotherapy variable is the lagged number of "preferred" OncologySTAT regimens (OncSTAT_pref $f_{c, t-2}$ ). The coefficients in models 13-14 are larger than the corresponding coefficients in models 9-12, which suggests that the introduction of a preferred regimen reduces mortality more than the introduction of a non-preferred regimen. This finding is consistent with our estimates based on U.S. time-series data (Table 5).

Models 15-16 include the lagged number of "non-preferred" OncologySTAT regimens as well as the lagged number of "preferred" OncologySTAT regimens. When we do not control for GDP and the other factors (model 15), the coefficient on OncSTAT_nonpref $f_{c, t-2}$ is positive and marginally significant $(\mathrm{p}$-value $=0.0547$ ), suggesting that, holding constant the number of preferred regimens, an increase in the number of non-preferred regimens increases the mortality rate. However, when we control for GDP and the other factors (model 16), the coefficient on OncSTAT_nonpref c,t-2 $_{\text {is }}$ far from significant, suggesting that the mortality rate is reduced by the introduction of preferred regimens, but is not affected by the introduction of non-preferred regimens.

\section{Summary and discussion}

Two reliable sources indicate that there were no innovations in chemotherapy for myeloma patients during the period 1977-1997, but that there have been numerous innovations since 1997. In this paper, we investigated the impact of recent chemotherapy innovation on the longevity of myeloma patients using two different approaches. Due to data limitations, in both

\footnotetext{
${ }^{22}$ The positive GDP coefficient, which signifies that countries with higher income growth have higher growth in myeloma mortality, may be a reflection of competing risks. When a country becomes richer, fewer people die from infectious diseases (tuberculosis and HIV), and more people die of myeloma and other cancers.
} 
approaches, the treatment variable is the (current or lagged) number of chemotherapy regimens that could have been used to treat myeloma patients.

First, we investigated the impact of chemotherapy innovation using annual U.S. timeseries data during the period 1975-2009. The sharp discontinuity in the number of available chemotherapy regimens enables us to identify this impact. The 5-year relative survival rate increased almost three times as rapidly during the period 1997-2005 as it did during the preceding twenty years. The relative survival of Australian myeloma patients also grew much more rapidly after 1999 than it did before then. We estimated that the increase in the number of chemotherapy regimens preferred by specialists explains $75 \%$ of the 8.5 percentage point increase in the relative survival rate of American myeloma patients during 1997-2005.

The average annual rate of increase of life expectancy at time of diagnosis was over five times as large during 1997-2005 as it had been during 1975-1997. Between 1997 and 2005, life expectancy at time of diagnosis increased by 1.53 years, from 4.15 to 5.68 years. We estimate that almost two-thirds ( 0.986 years) of the increase in life expectancy was due to the increase in the number of chemotherapy regimens preferred by specialists.

By combining this estimate of the increase in life expectancy due to chemotherapy innovation with data on myeloma incidence and drug expenditure, we can obtain a rough estimate of the incremental cost-effectiveness of (cost per life-year gained from) new myeloma treatments in the U.S. In 2005, the (age-adjusted) myeloma incidence rate was 6.08 cases per 100,000 population (Howlader et al., 2012). The 2005 U.S. population was 296.4 million, so the estimated number of new myeloma cases in 2005 was $17,868(=6.05 * 2964.1) .{ }^{23}$ We estimate that the life expectancy of these 17,868 people was increased by almost one year, on average, by the post-1997 introduction of new chemotherapy regimens now preferred by specialists. Hence, the annual number of life-years gained from that innovation is about 17,617 $(=.986$ years/case * 17,868 cases). As shown in Tables 1 and 2, all of the post-1997 chemotherapy innovations include the three new drugs: thalidomide, bortezomib, and lenalidomide. Expenditure on these three drugs probably accounts for almost the entire cost of post-1997 chemotherapy innovation to payers and patients. ${ }^{24}$ According to IMS Health, total U.S. expenditure ${ }^{25}$ on these drugs was

\footnotetext{
${ }^{23}$ This estimate may be conservative: the NCI estimates that there were 21,700 new cases of multiple myeloma in the United States in 2012 (http://www.cancer.gov/cancertopics/types/myeloma).

${ }^{24}$ Since other drugs included in post-1997 regimens are quite old, they are likely to be available in generic form and therefore inexpensive.
} 
$\$ 510$ million in 2005, and \$1081 million in 2010; average annual expenditure during 2005-2010 was $\$ 802$ million. This implies that the cost per U.S. life-year gained from post-1997 chemotherapy innovation was $\$ 45,551$ (= $\$ 802$ million / 17,868 life-years gained).

Our study includes only direct treatment costs for the new substances and no possible cost offsets of other treatment components. This may lead to overestimation of the incremental cost of treatment compared to best standard of care. Taking all treatment components into account, Goss et al. (2006) compares the cost-effectiveness of lenalidomide vs. best supportive care and finds that the incremental costs per QALY gained amount only to about 35.050 US \$ in 2004, which is somewhat lower than the estimates of additional drug costs found in this study. Yet, our cost estimates are only about $15 \%$ of Aldy and Viscusi (2008) estimate $(\$ 300,000)$ of the average value of (willingness to pay for) an American life-year.

We also investigated the impact of chemotherapy innovation on the myeloma mortality rate using longitudinal country-level data on 26 countries during the period 2005-2009. Some chemotherapy regimens became available later in some countries than in others, or did not become available in some countries by the end of 2010. We found that countries that had larger increases in the number of chemotherapy regimens had larger subsequent declines in myeloma mortality rates. The estimates implied that chemotherapy innovation reduced the age-adjusted mortality rate by about $3.1 \%$ during the period 2005-2009.

\section{Ethics}

This study did not require approval from an ethics committee.

\footnotetext{
${ }^{25}$ These figures may overstate expenditure because they do not account for manufacturer rebates.
} 


\section{References}

Aldy, J. E. \& Viscusi, W. K. 2008. Adjusting the value of a statistical life for age and cohort effects. Review of Economics and Statistics, 90, 573-581.

Barlogie, B., Desikan, R., Eddlemon, P., Spencer, T., Zeldis, J., Munshi, N., et al. 2001. Extended survival in advanced and refractory multiple myeloma after single-agent thalidomide: identification of prognostic factors in a phase 2 study of 169 patients. Blood, 98, 492-4.

Baz, R., Miladinovic, B., Patel, A., Ho, V. Q., Shain, K. H., Alsina, M., et al. 2013. Sequence of novel agents in multiple myeloma: an instrumental variable analysis. Leuk Res, 37, 1077-82.

Brenner, H. \& Gefeller, O. 1996. An alternative approach to monitoring cancer patient survival. Cancer, 78, 2004-10.

Brenner, H. \& Hakulinen, T. 2002. Up-to-date long-term survival curves of patients with cancer by period analysis. Journal of Clinical Oncology, 20, 826-32.

Cook, R. 2008. Economic and clinical impact of multiple myeloma to managed care. Journal of managed care pharmacy: JMCP, 14, 19.

Ederer, F., Axtell, L. M. \& Cutler, S. J. 1961. The relative survival rate: a statistical methodology. Natl Cancer Inst Monogr, 6, 101-21.

Elsevier 2012. The Elsevier guide to oncology drugs \& regimens, Elsevier Science Health Science.

Facon, T., Mary, J. Y., Hulin, C., Benboubker, L., Attal, M., Pegourie, B., et al. 2007. Melphalan and prednisone plus thalidomide versus melphalan and prednisone alone or reduced-intensity autologous stem cell transplantation in elderly patients with multiple myeloma (IFM 99-06): a randomised trial. Lancet, 370, 1209-18.

Goss, T. F., Szende, A., Schaefer, C., Totten, P. J., Knight, R., Jadersten, M., et al. 2006. Cost effectiveness of lenalidomide in the treatment of transfusion-dependent myelodysplastic syndromes in the United States. Cancer Control, 13, 17.

Harousseau, J. L., Mathiot, C. \& Attal, M. 2007. VELCADE/Dexamethasone (vel/D) versus VAD as induction treatment prior to autologous stem cell transplantion (ASCT) in newly diagnosed multiple myeloma (MM): updated results of the IFM 2005/01 trial. Blood (ASH Annual Meeting), 110.

Harrison, T. 2013. Promising new agents for multiple myeloma. Available online: http://www.pmlive.com/pharma_news/promising_new_agents for_multiple myeloma 474478 . [accessed 17/12/2013]

Howlader, N., Noone, A., Krapcho, M., Neyman, N., Aminou, R., Waldron, W., et al. 2012. SEER Cancer Statistics Review, 1975-2009 (Vintage 2009 Populations) National Cancer Institue based 
on November 2011 SEER data submission, posted to the SEER web site, April 2012. Bethesda, MD.

Http://www.Cancer.Gov/Cancertopics/Types/Myeloma. [Accessed 20/12/2012].

Hulin , C. F., T; Rodon, P; 2007. Melphalan-prednisonethalidomide (MP-T) demonstrates a significant survival advantage in elderly patients $\geq 75$ years with multiple myeloma compared with melphalan-prednisone (MP) in a randomized, double-blind, placebo-controlled trial. Blood (ASH Annual Meeting), 110.

Kleinbaum, D. G. \& Mitchel, K. 2012. Survival Analysis Springer Science+Business Media, LLC

Kumar, A., Hozo, I., Wheatley, K. \& Djulbegovic, B. 2011. Thalidomide versus bortezomib based regimens as first-line therapy for patients with multiple myeloma: a systematic review. Am $J$ Hematol, 86, 18-24.

Kumar, V. \& Chhibber, S. 2011. Thalidomide: an old drug with new action. J Chemother, 23, 326-34. Lichtenberg, F. R. 2006. The impact of increased utilization of HIV drugs on longevity and medical expenditure: an assessment based on aggregate U.S. time-series data. Expert Review of Pharmacoeconomics and Outcomes Research, 6, 425 - 436.

Lichtenberg, F. R. 2010. Are Increasing 5-Year Survival Rates Evidence of Success Against Cancer? A Reexamination Using Data from the U.S. and Australia. Forum for Health Economics \& Policy (Health Economics), 13.

Lichtenberg, F. R. 2013a. The Effect of Pharmaceutical Innovation on Longevity: Patient Level Evidence from the 1996-2002 Medical Expenditure Panel Survey and Linked Mortality Public-use Files. Forum for Health Economics and Policy 16, 1-33.

Lichtenberg, F. R. 2013b. The impact of therapeutic procedure innovation on hospital patient longevity: Evidence from Western Australia, 2000-2007. Social Science and Medicine, 77, 50-9.

Palumbo, A., Bringhen, S., Caravita, T., Merla, E., Capparella, V., Callea, V., et al. 2006. Oral melphalan and prednisone chemotherapy plus thalidomide compared with melphalan and prednisone alone in elderly patients with multiple myeloma: randomised controlled trial. Lancet, 367, 825-31.

Ramesh, N. H., Maike. 2013. New Study Further Documents Trends In Stem Cell Transplantation For Multiple Myeloma. The Myeloma Beacon [Online]. Available: http://www.myelomabeacon.com/news/2013/05/30/trends-stem-cell-transplantation-multiplemyeloma/.

Raab, M. S., Podar, K., Breitkreutz, I., Richardson, P. G. \& Anderson, K. C. 2009. Multiple myeloma. Lancet, 374, 324-339.

SEER Cancer Statistics Review 1975-2009 (Vintage 2009 Populations): Technical Notes, http://seer.cancer.gov/csr/1975_2009_pops09/results_figure/sect_01_intro2_24pgs.pdf 
Surveillance Epidemiology and End Results (SEER) Program; (www.seer.cancer.gov) SEER*Stat Database:

Incidence and Mortality- SEER 9 Regs Research Data, Nov 2011 Sub (1973-2009) National Cancer Institute, DCCPS, Surveillance Research Program, Surveillance Systems Branch, Underlying mortality data provided by NCHS (www.cdc.gov/nchs).

Thaul, S. 2012. How FDA Approves Drugs and Regulates Their Safety and Effectiveness. In: Congresional Research Service (ed.).

World Health Organization Cancer Mortality Database. WHO. http://www-dep.iarc.fr/WHOdb/WHOdb.htm 


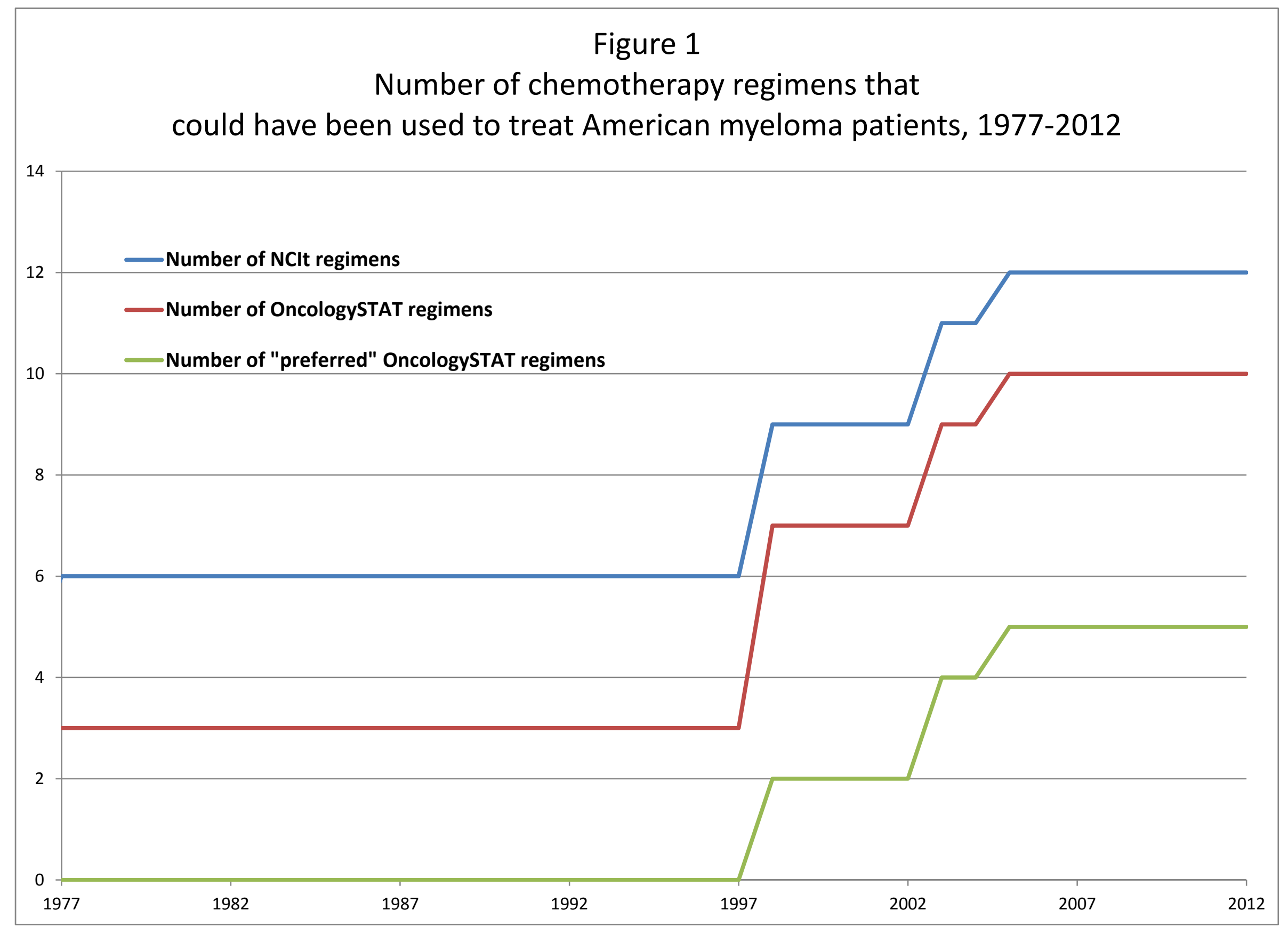




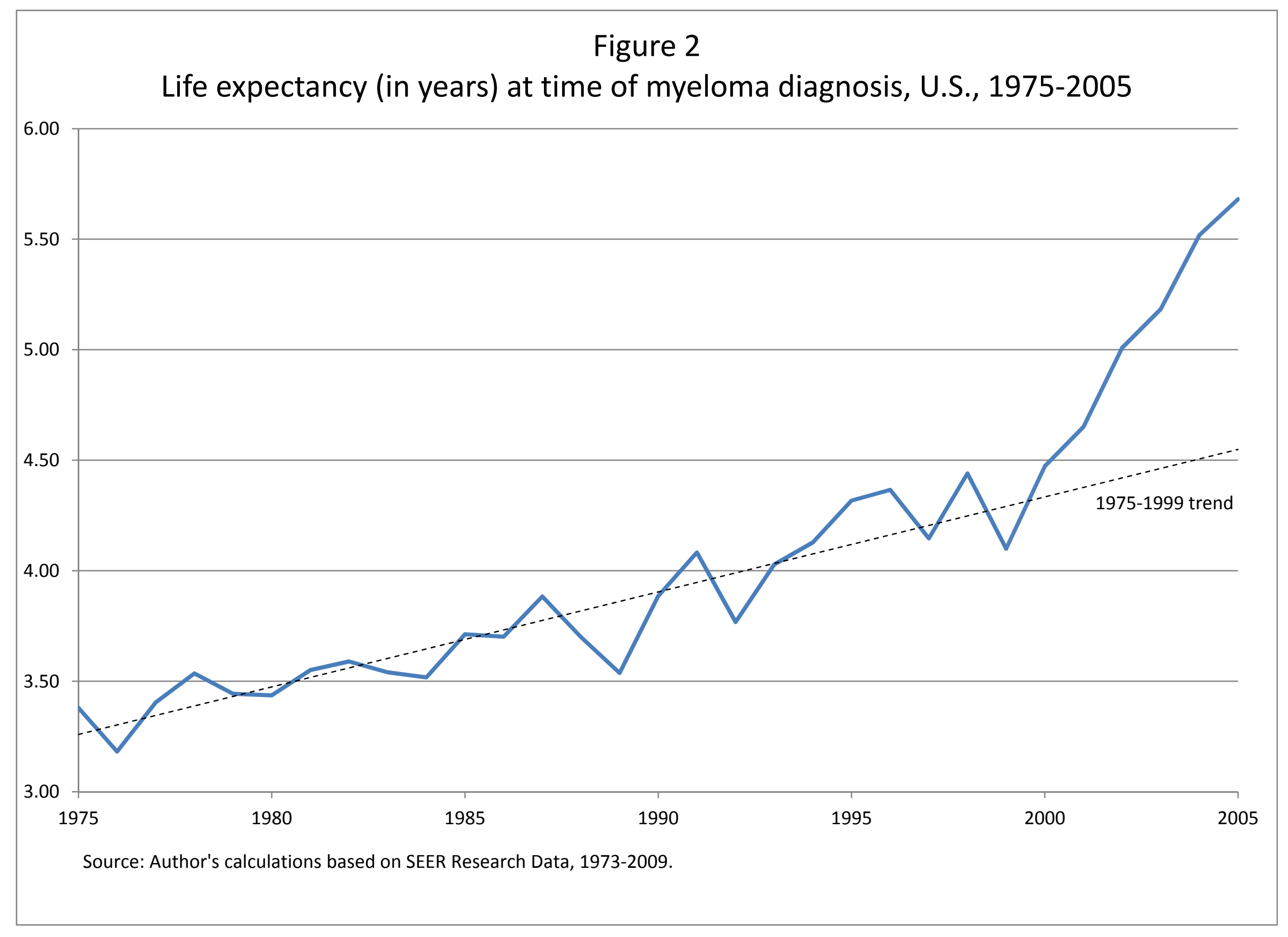




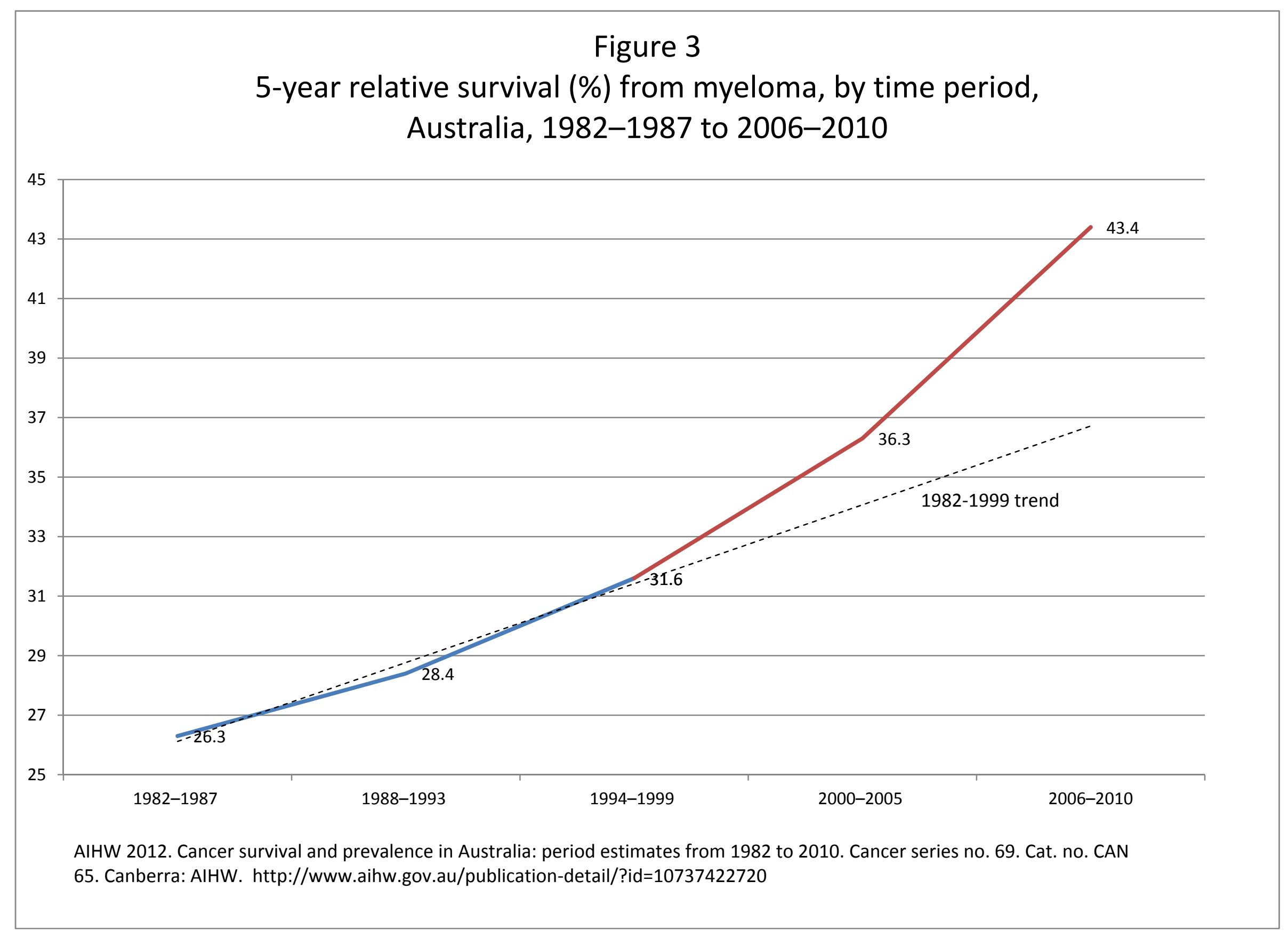


Table 1

National Cancer Institute Thesaurus chemotherapy regimens

\begin{tabular}{|c|c|c|c|c|c|c|c|c|c|c|c|c|c|}
\hline & & \multicolumn{12}{|c|}{ Drug } \\
\hline & & 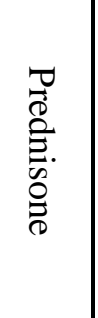 & 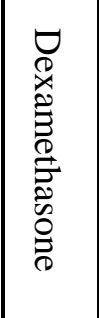 & 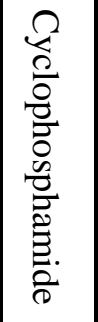 & 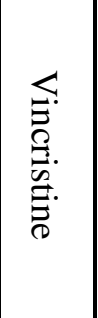 & 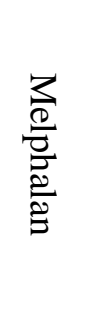 & 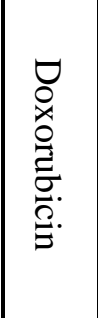 & 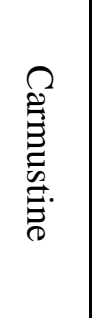 & $\begin{array}{l}\stackrel{0}{0} \\
\frac{0}{0} \\
\stackrel{0}{\Xi} .\end{array}$ & 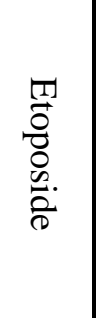 & 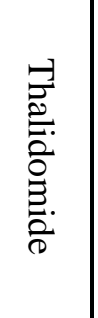 & 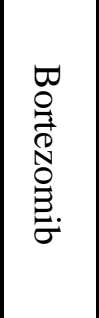 & 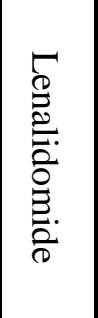 \\
\hline & $\begin{array}{l}\text { Drug } \\
\text { year }\end{array}$ & 1955 & 1958 & 1959 & 1963 & 1964 & 1974 & 1977 & 1978 & 1983 & 1998 & 2003 & 2005 \\
\hline regimen & Regim & en yea & & & & & & & & & & & \\
\hline MP-Myeloma Regimen & 1964 & $\mathrm{x}$ & & & & $\mathrm{x}$ & & & & & & & \\
\hline $\begin{array}{l}\text { Cyclophosphamide-VAD } \\
\text { Regimen }\end{array}$ & 1974 & & $x$ & $x$ & $X$ & & $X$ & & & & & & \\
\hline DVD Regimen & 1974 & & $\mathrm{x}$ & & $\mathrm{x}$ & & $\mathrm{x}$ & & & & & & \\
\hline VAD Regimen & 1974 & & $\mathrm{x}$ & & $\mathrm{x}$ & & $\mathrm{x}$ & & & & & & \\
\hline VBMCP Regimen & 1977 & $\mathrm{x}$ & & $\mathrm{X}$ & $\mathrm{X}$ & $\mathrm{x}$ & & $\mathrm{x}$ & & & & & \\
\hline VMCP-VBAP Regimen & 1977 & $\mathrm{x}$ & & $\mathrm{x}$ & $\mathrm{x}$ & $\mathrm{x}$ & $\mathrm{x}$ & $\mathrm{x}$ & & & & & \\
\hline DT-PACE Regimen & 1998 & & $\mathrm{x}$ & $\mathrm{X}$ & & & $\mathrm{x}$ & & $\mathrm{x}$ & $X$ & $X$ & & \\
\hline MPT Regimen & 1998 & $\mathrm{x}$ & & & & $\mathrm{x}$ & & & & & $\mathrm{x}$ & & \\
\hline $\begin{array}{l}\text { Thalidomide-Dexamethasone } \\
\text { Regimen }\end{array}$ & 1998 & & $\mathrm{X}$ & & & & & & & & $\mathrm{X}$ & & \\
\hline $\begin{array}{l}\text { Bortezomib-Dexamethasone } \\
\text { Regimen }\end{array}$ & 2003 & & $\mathrm{X}$ & & & & & & & & & $\mathrm{X}$ & \\
\hline MPB Regimen & 2003 & $\mathrm{x}$ & & & & $\mathrm{x}$ & & & & & & $\mathrm{x}$ & \\
\hline $\begin{array}{l}\text { Lenalidomide-Dexamethasone } \\
\text { Regimen }\end{array}$ & 2005 & & $\mathrm{X}$ & & & & & & & & & $\mathrm{X}$ & $\mathrm{X}$ \\
\hline
\end{tabular}

The "drug year" is the initial year of FDA approval year of the drug.

The "regimen year" is the FDA approval year of the most recently approved drug included in the regimen. 
Table 2

\section{OncologySTAT chemotherapy regimens}

\begin{tabular}{|c|c|c|c|c|c|c|c|c|c|c|}
\hline & & & \multicolumn{8}{|c|}{ Drug } \\
\hline & & & 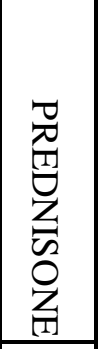 & 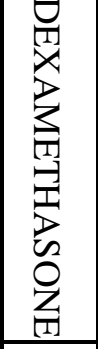 & 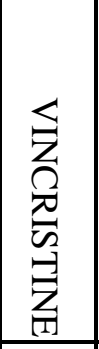 & 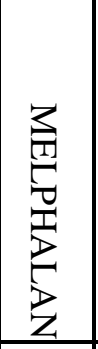 & 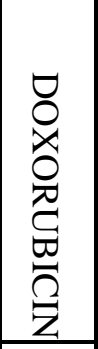 & 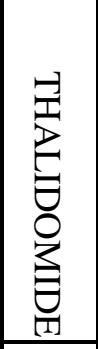 & 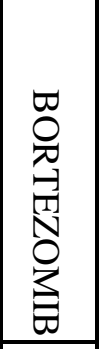 & 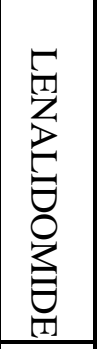 \\
\hline & & Drug year & 1955 & 1958 & 1963 & 1964 & 1974 & 1998 & 2003 & 2005 \\
\hline Regimen & $\begin{array}{l}\text { Preferred } \\
\text { regimen? }\end{array}$ & $\begin{array}{l}\text { Regimen } \\
\text { year }\end{array}$ & & & & & & & & \\
\hline MP (melphalan, prednisone & No & 1964 & $\mathrm{x}$ & & & $\mathrm{x}$ & & & & \\
\hline $\begin{array}{l}\text { DVd (pegylated liposomal } \\
\text { doxorubicin, vincristine, } \\
\text { dexamethasone) }\end{array}$ & No & 1974 & & $\mathrm{x}$ & $\mathrm{x}$ & & $\mathrm{X}$ & & & \\
\hline $\begin{array}{l}\text { VAD (vincristine, doxorubicin } \\
\text { [Adriamycin], dexamethasone) }\end{array}$ & No & 1974 & & $\mathrm{X}$ & $\mathrm{X}$ & & $\mathrm{X}$ & & & \\
\hline Thalidomide, dexamethasonı & No & 1998 & & $\mathrm{x}$ & & & & $\mathrm{x}$ & & \\
\hline $\begin{array}{l}\text { DVd-T (pegylated liposomal } \\
\text { doxorubicin, vincristine, } \\
\text { dexamethasone, thalidomide) }\end{array}$ & No & 1998 & & $\mathrm{x}$ & $\mathrm{X}$ & & $\mathrm{X}$ & $\mathrm{X}$ & & \\
\hline $\begin{array}{l}\text { Melphalan, prednisone, thalidomide } \\
\text { (MPT) }\end{array}$ & Yes & 1998 & $\mathrm{X}$ & & & $\mathrm{x}$ & & $\mathrm{X}$ & & \\
\hline Thalidomide & Yes & 1998 & & & & & & $\mathrm{x}$ & & \\
\hline Bortezomib & Yes & 2003 & & & & & & & $\mathrm{x}$ & \\
\hline Bortezomib, liposomal doxorubicin & Yes & 2003 & & & & & $\mathrm{x}$ & & $\mathrm{x}$ & \\
\hline Lenalidomide, dexamethason & Yes & 2005 & & $\mathrm{x}$ & & & & & & $\mathrm{x}$ \\
\hline
\end{tabular}

The "drug year" is the initial year of FDA approval year of the drug.

The "regimen year" is the FDA approval year of the most recently approved drug included in the regimen. 
Table 3

Estimates of Weibull distribution parameters and related statistics, by year of myeloma diagnosis

\begin{tabular}{|c|c|c|c|c|c|}
\hline Year of diagnosis & $\begin{array}{c}\text { Number } \\
\text { of } \\
\text { patients }\end{array}$ & $\begin{array}{l}\text { \% of patients } \\
\text { with right- } \\
\text { censored } \\
\text { survival times }\end{array}$ & $\begin{array}{c}\text { scale } \\
\text { parameter } \\
(\lambda)\end{array}$ & \begin{tabular}{|c|} 
shape \\
parameter \\
$(\mathbf{k})$
\end{tabular} & $\begin{array}{c}\text { life expectancy } \\
(\lambda \Gamma(1+(1 / k))))\end{array}$ \\
\hline 1975 & 767 & $1 \%$ & 3.035 & 0.820 & 3.38 \\
\hline 1976 & 806 & $0 \%$ & 2.861 & 0.821 & 3.18 \\
\hline 1977 & 811 & $0 \%$ & 3.060 & 0.821 & 3.40 \\
\hline 1978 & 791 & $1 \%$ & 3.178 & 0.821 & 3.54 \\
\hline 1979 & 812 & $0 \%$ & 3.075 & 0.814 & 3.44 \\
\hline 1980 & 838 & $0 \%$ & 3.174 & 0.857 & 3.44 \\
\hline 1981 & 860 & $1 \%$ & 3.187 & 0.819 & 3.55 \\
\hline 1982 & 944 & $1 \%$ & 3.338 & 0.866 & 3.59 \\
\hline 1983 & 954 & $1 \%$ & 3.320 & 0.879 & 3.54 \\
\hline 1984 & 996 & $1 \%$ & 3.213 & 0.842 & 3.52 \\
\hline 1985 & 957 & $1 \%$ & 3.473 & 0.875 & 3.71 \\
\hline 1986 & 1004 & $1 \%$ & 3.355 & 0.832 & 3.70 \\
\hline 1987 & 1136 & $2 \%$ & 3.619 & 0.870 & 3.88 \\
\hline 1988 & 1044 & $2 \%$ & 3.505 & 0.895 & 3.70 \\
\hline 1989 & 1065 & $2 \%$ & 3.284 & 0.864 & 3.54 \\
\hline 1990 & 1142 & $3 \%$ & 3.494 & 0.822 & 3.89 \\
\hline 1991 & 1235 & $3 \%$ & 3.758 & 0.852 & 4.08 \\
\hline 1992 & 1243 & $4 \%$ & 3.433 & 0.838 & 3.77 \\
\hline 1993 & 1191 & $5 \%$ & 3.653 & 0.832 & 4.03 \\
\hline 1994 & 1222 & $5 \%$ & 3.801 & 0.852 & 4.13 \\
\hline 1995 & 1251 & $7 \%$ & 3.943 & 0.841 & 4.32 \\
\hline 1996 & 1288 & $8 \%$ & 3.848 & 0.798 & 4.37 \\
\hline 1997 & 1385 & $8 \%$ & 3.806 & 0.848 & 4.15 \\
\hline 1998 & 1357 & $11 \%$ & 4.032 & 0.834 & 4.44 \\
\hline 1999 & 1321 & $11 \%$ & 3.739 & 0.840 & 4.10 \\
\hline 2000 & 1440 & $15 \%$ & 4.090 & 0.843 & 4.47 \\
\hline 2001 & 1407 & $18 \%$ & 4.168 & 0.818 & 4.65 \\
\hline 2002 & 1471 & $23 \%$ & 4.469 & 0.813 & 5.01 \\
\hline 2003 & 1472 & $28 \%$ & 4.671 & 0.824 & 5.18 \\
\hline 2004 & 1497 & $34 \%$ & 4.841 & 0.793 & 5.52 \\
\hline 2005 & 1595 & $40 \%$ & 4.872 & 0.770 & 5.68 \\
\hline
\end{tabular}


Table 4

U.S. time-series data on myeloma, 1975-2009

\begin{tabular}{|c|c|c|c|c|c|}
\hline Year & $\begin{array}{l}\text { Number of } \\
\text { NCI } \\
\text { Thesaurus } \\
\text { regimens }\end{array}$ & $\begin{array}{c}\text { Number of } \\
\text { OncologySTAT } \\
\text { regimens }\end{array}$ & $\begin{array}{c}\text { Number of } \\
\text { "preferred" } \\
\text { OncologySTAT } \\
\text { regimens }\end{array}$ & $\begin{array}{l}5 \text {-year } \\
\text { relative } \\
\text { survival } \\
\text { rate }\end{array}$ & $\begin{array}{c}\text { Estimated life } \\
\text { expectancy (in } \\
\text { years) at time of } \\
\text { diagnosis }\end{array}$ \\
\hline 1975 & 4 & 3 & 0 & $26.8 \%$ & 3.38 \\
\hline 1976 & 4 & 3 & 0 & $23.9 \%$ & 3.18 \\
\hline 1977 & 6 & 3 & 0 & $24.7 \%$ & 3.40 \\
\hline \begin{tabular}{|l|}
1978 \\
\end{tabular} & 6 & 3 & 0 & $26.9 \%$ & 3.54 \\
\hline 1979 & 6 & 3 & 0 & $25.1 \%$ & 3.44 \\
\hline \begin{tabular}{|l|}
1980 \\
\end{tabular} & 6 & 3 & 0 & $26.0 \%$ & 3.44 \\
\hline 1981 & 6 & 3 & 0 & $27.0 \%$ & 3.55 \\
\hline \begin{tabular}{|l|}
1982 \\
\end{tabular} & 6 & 3 & 0 & $28.4 \%$ & 3.59 \\
\hline 1983 & 6 & 3 & 0 & $27.9 \%$ & 3.54 \\
\hline 1984 & 6 & 3 & 0 & $26.3 \%$ & 3.52 \\
\hline 1985 & 6 & 3 & 0 & $27.0 \%$ & 3.71 \\
\hline 1986 & 6 & 3 & 0 & $29.0 \%$ & 3.70 \\
\hline \begin{tabular}{|l|}
1987 \\
\end{tabular} & 6 & 3 & 0 & $27.7 \%$ & 3.88 \\
\hline 1988 & 6 & 3 & 0 & $29.0 \%$ & 3.70 \\
\hline \begin{tabular}{|l|}
1989 \\
\end{tabular} & 6 & 3 & 0 & $26.0 \%$ & 3.54 \\
\hline 1990 & 6 & 3 & 0 & $30.2 \%$ & 3.89 \\
\hline 1991 & 6 & 3 & 0 & $31.0 \%$ & 4.08 \\
\hline \begin{tabular}{|l|}
1992 \\
\end{tabular} & 6 & 3 & 0 & $28.5 \%$ & 3.77 \\
\hline 1993 & 6 & 3 & 0 & $30.7 \%$ & 4.03 \\
\hline 1994 & 6 & 3 & 0 & $30.7 \%$ & 4.13 \\
\hline 1995 & 6 & 3 & 0 & $32.8 \%$ & 4.32 \\
\hline 1996 & 6 & 3 & 0 & $33.7 \%$ & 4.37 \\
\hline 1997 & 6 & 3 & 0 & $32.3 \%$ & 4.15 \\
\hline 1998 & 9 & 7 & 2 & $33.3 \%$ & 4.44 \\
\hline \begin{tabular}{|l|}
1999 \\
\end{tabular} & 9 & 7 & 2 & $31.6 \%$ & 4.10 \\
\hline 2000 & 9 & 7 & 2 & $33.7 \%$ & 4.47 \\
\hline 2001 & 9 & 7 & 2 & $35.7 \%$ & 4.65 \\
\hline 2002 & 9 & 7 & 2 & $38.3 \%$ & 5.01 \\
\hline 2003 & 11 & 9 & 4 & $40.1 \%$ & 5.18 \\
\hline 2004 & 11 & 9 & 4 & $41.6 \%$ & 5.52 \\
\hline 2005 & 12 & 10 & 5 & $40.8 \%$ & 5.68 \\
\hline 2006 & 12 & 10 & 5 & & \\
\hline 2007 & 12 & 10 & 5 & & \\
\hline 2008 & 12 & 10 & 5 & & \\
\hline 2009 & 12 & 10 & 5 & & \\
\hline
\end{tabular}


Table 5

Estimates of models of 5-year relative survival rate and life expectancy at time of diagnosis

\begin{tabular}{|c|c|c|c|c|c|c|c|c|}
\hline Model & 1 & 2 & 3 & 4 & 5 & 6 & 7 & 8 \\
\hline Dep. Var. & \multicolumn{4}{|c|}{ 5-year relative survival rate } & \multicolumn{4}{|c|}{ Life expectancy at time of diagnosis } \\
\hline & & & & & & & & \\
\hline \multicolumn{9}{|l|}{ Regressor } \\
\hline \multicolumn{9}{|c|}{ Number of NCI Thesaurus regimens } \\
\hline Estimate & 0.007472 & & & & 0.1245 & & & \\
\hline $\mathrm{t}$ Value & 2.16 & & & & 2.86 & & & \\
\hline Approx $\operatorname{Pr}>|t|$ & 0.0398 & & & & 0.008 & & & \\
\hline \multicolumn{9}{|c|}{ Number of OncologySTAT regimens } \\
\hline Estimate & & 0.0072 & & & & 0.1082 & & \\
\hline t Value & & 2.76 & & & & 3.08 & & \\
\hline Approx $\operatorname{Pr}>|t|$ & & 0.0103 & & & & 0.0048 & & \\
\hline & & & & & & & & \\
\hline \multicolumn{9}{|c|}{ Number of "preferred" OncologySTAT regimens } \\
\hline Estimate & & & 0.0128 & 0.0188 & & & 0.1971 & 0.3167 \\
\hline $\mathrm{t}$ Value & & & 3.78 & 3.9 & & & 4.64 & 6.16 \\
\hline Approx $\operatorname{Pr}>|\mathrm{t}|$ & & & 0.0008 & 0.0006 & & & $<.0001$ & $<.0001$ \\
\hline \multicolumn{9}{|c|}{ Number of "non-preferred" OncologySTAT regimens } \\
\hline Estimate & & & & -0.0116 & & & & -0.2256 \\
\hline t Value & & & & -1.44 & & & & -2.65 \\
\hline Approx $\operatorname{Pr}>|t|$ & & & & 0.1606 & & & & 0.0135 \\
\hline \multicolumn{9}{|l|}{ Year } \\
\hline Estimate & 0.003414 & 0.003414 & 0.003311 & 0.003507 & 0.0425 & 0.045 & 0.0417 & 0.0445 \\
\hline t Value & 4.19 & 5.03 & 6.08 & 7.02 & 3.79 & 4.6 & 5.89 & 8.52 \\
\hline Approx $\operatorname{Pr}>|t|$ & 0.0003 & $<.0001$ & $<.0001$ & $<.0001$ & 0.0008 & $<.0001$ & $<.0001$ & $<.0001$ \\
\hline \multicolumn{9}{|l|}{ Intercept } \\
\hline Estimate & -6.539 & -6.5181 & -6.2937 & -6.647 & -81.3424 & -85.9534 & -79.021 & -84.0507 \\
\hline t Value & -4.08 & -4.86 & -5.81 & -6.75 & -3.69 & -4.44 & -5.63 & -8.16 \\
\hline Approx $\operatorname{Pr}>|t|$ & 0.0004 & $<.0001$ & $<.0001$ & $<.0001$ & 0.001 & 0.0001 & $<.0001$ & $<.0001$ \\
\hline \multicolumn{9}{|c|}{ Autoregressive parameter } \\
\hline Coefficient & -0.29407 & -0.30035 & -0.17598 & -0.04093 & -0.43191 & -0.45681 & -0.30532 & -0.00364 \\
\hline t Value & -1.6 & -1.64 & -0.93 & -0.21 & -2.49 & -2.67 & -1.67 & -0.02 \\
\hline Durbin-Watson & 1.8657 & 1.8621 & 1.8774 & 1.8712 & 1.827 & 1.7833 & 1.8753 & 1.9711 \\
\hline Total R-Square & $89.4 \%$ & $90.0 \%$ & $90.8 \%$ & $91.3 \%$ & $92.4 \%$ & $92.5 \%$ & $93.3 \%$ & $94.1 \%$ \\
\hline
\end{tabular}


Table 6

First post-1998 year in which each drug was sold in each country

\begin{tabular}{|c|c|c|c|c|c|c|c|c|c|c|c|c|}
\hline & \multicolumn{12}{|c|}{ Molecule } \\
\hline Country & 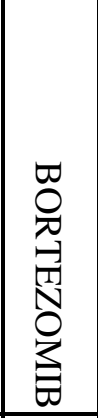 & 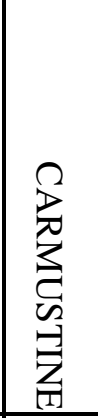 & 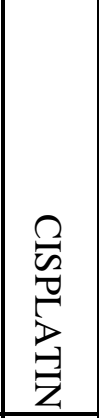 & 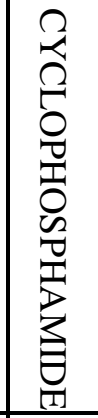 & 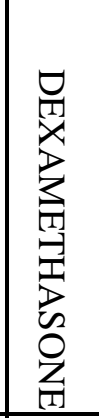 & 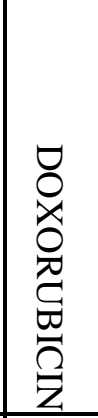 & 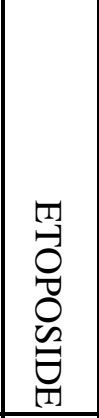 & 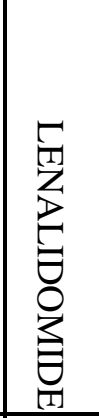 & 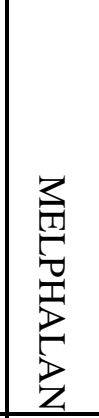 & 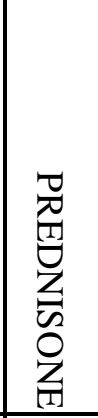 & 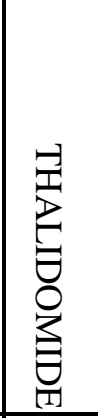 & 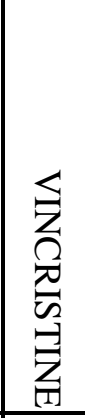 \\
\hline Argentina & & & 1999 & 1999 & 1999 & 1999 & 1999 & & 1999 & 1999 & & 1999 \\
\hline Australia & 2006 & 1999 & 1999 & 1999 & 1999 & 1999 & 1999 & 2008 & 1999 & 1999 & 2003 & 1999 \\
\hline Austria & 2004 & 2000 & 1999 & 1999 & 1999 & 1999 & 1999 & 2007 & 1999 & 1999 & 2008 & 1999 \\
\hline Belgium & 2005 & 1999 & 1999 & 1999 & 1999 & 1999 & 1999 & 2008 & 1999 & 1999 & & 1999 \\
\hline Brazil & 2010 & 2002 & 1999 & 1999 & 1999 & 1999 & 1999 & & 1999 & 1999 & & 1999 \\
\hline Canada & 2005 & 1999 & 1999 & 1999 & 1999 & 1999 & 1999 & & 1999 & 1999 & & 1999 \\
\hline Colombia & & & 2002 & 1999 & 1999 & 1999 & 1999 & & 1999 & 1999 & 2005 & 1999 \\
\hline Egypt & & & 1999 & 1999 & 1999 & 1999 & 1999 & & 1999 & 1999 & & 1999 \\
\hline Finland & 2005 & 1999 & 1999 & 1999 & 1999 & 1999 & 1999 & 2008 & 1999 & 1999 & 2008 & 1999 \\
\hline France & 2004 & 1999 & 1999 & 1999 & 1999 & 1999 & 1999 & 2007 & 1999 & 1999 & 1999 & 1999 \\
\hline Germany & 2004 & 1999 & 1999 & 1999 & 1999 & 1999 & 1999 & 2007 & 1999 & 1999 & 2009 & 1999 \\
\hline Greece & 2008 & & 1999 & 1999 & 1999 & 1999 & 1999 & & 1999 & & & 1999 \\
\hline Italy & 2005 & 2006 & 1999 & 1999 & 1999 & 1999 & 1999 & 2008 & 1999 & 1999 & 2009 & 1999 \\
\hline Japan & 2007 & & 1999 & 1999 & 1999 & 1999 & 1999 & 2010 & 1999 & & 2009 & 1999 \\
\hline Mexico & 2005 & 2004 & 1999 & 1999 & 1999 & 1999 & 1999 & & 1999 & 1999 & 2003 & 1999 \\
\hline Netherlands & 2005 & & 1999 & 1999 & 1999 & 1999 & 1999 & 2007 & 1999 & 1999 & & 1999 \\
\hline Philippines & & & 1999 & 1999 & 1999 & 1999 & 1999 & & 1999 & 1999 & 2007 & 1999 \\
\hline Poland & 2008 & 1999 & 1999 & 1999 & 1999 & 1999 & 1999 & & 1999 & 1999 & 2004 & 1999 \\
\hline Portugal & & & & 1999 & 1999 & & & & 1999 & 1999 & & \\
\hline \begin{tabular}{|l} 
Singapore \\
\end{tabular} & 2005 & & 1999 & 1999 & 1999 & 1999 & 1999 & 2009 & 1999 & 1999 & & 1999 \\
\hline South Africa & 2007 & 2007 & 1999 & 1999 & 1999 & 1999 & 1999 & & 1999 & 1999 & 2007 & 1999 \\
\hline \begin{tabular}{|l|} 
Spain \\
\end{tabular} & 2004 & 1999 & 1999 & 1999 & 1999 & 1999 & 1999 & 2008 & 1999 & 1999 & & 1999 \\
\hline Sweden & 2004 & & 1999 & 1999 & 1999 & 1999 & 1999 & 2008 & 1999 & 1999 & 2008 & 1999 \\
\hline Switzerland & 2005 & 1999 & 1999 & 1999 & 1999 & 1999 & 1999 & 2007 & 1999 & 1999 & & 1999 \\
\hline United Kingdom & 2004 & 1999 & 1999 & 1999 & 1999 & 1999 & 1999 & 2007 & 1999 & 1999 & 2008 & 1999 \\
\hline United States of America & 2003 & 1999 & 1999 & 1999 & 1999 & 1999 & 1999 & 2006 & 1999 & 1999 & 1999 & 1999 \\
\hline
\end{tabular}

A blank cell indicates that the drug was not sold in that country by the end of 2010 .

Source: Austhor's calculations based on IMS Health data. 
Table 7

Estimates of models of the age-adjusted myeloma mortality rate (eq. (3)) based on longitudinal country-level data, 2005-2009

Dependent variable: the log of the age-adjusted myeloma mortality rate in country $c$ in year $t$ All models include country and year fixed effects

\begin{tabular}{|c|c|c|c|c|c|c|c|c|}
\hline Model & 9 & 10 & 11 & 12 & 13 & 14 & 15 & 16 \\
\hline $\begin{array}{l}\text { Other time-varying } \\
\text { country attributes } \\
\text { included? }\end{array}$ & no & yes & no & yes & no & yes & no & yes \\
\hline \multirow{2}{*}{\multicolumn{9}{|c|}{\begin{tabular}{|l|l|l} 
Regressor & & \\
Number of NCI Thesaurus regimens in vear t-2
\end{tabular}}} \\
\hline & & & \multicolumn{6}{|c|}{ Number of NCI Thesaurus regimens in year $\mathrm{t}-2$} \\
\hline Estimate & -0.0162 & -0.0135 & & & & & & \\
\hline $\mathrm{Z}$ & -2.11 & -2.23 & & & & & & \\
\hline $\operatorname{Pr}>|\mathrm{Z}|$ & 0.0345 & 0.026 & & & & & & \\
\hline \multicolumn{9}{|c|}{ Number of OncologySTAT regimens in year $\mathrm{t}-2$} \\
\hline Estimate & & & -0.0159 & -0.0121 & & & & \\
\hline $\mathrm{Z}$ & & & -2.21 & -2.55 & & & & \\
\hline $\operatorname{Pr}>|\mathrm{Z}|$ & & & 0.0269 & 0.0108 & & & & \\
\hline \multicolumn{9}{|c|}{ Number of "preferred" OncologySTAT regimens in year t-2 } \\
\hline Estimate & & & & & -0.024 & -0.0175 & -0.0275 & -0.0192 \\
\hline $\mathrm{Z}$ & & & & & -2.71 & -2.44 & -3.05 & -1.93 \\
\hline $\operatorname{Pr}>|\mathrm{Z}|$ & & & & & 0.0067 & 0.0145 & 0.0023 & 0.0535 \\
\hline \multicolumn{9}{|c|}{ Number of "non-preferred" OncologySTAT regimens in year t-2 } \\
\hline Estimate & & & & & & & 0.0178 & 0.0061 \\
\hline $\mathrm{Z}$ & & & & & & & 1.92 & 0.4 \\
\hline $\operatorname{Pr}>|\mathrm{Z}|$ & & & & & & & 0.0547 & 0.69 \\
\hline
\end{tabular}

*Time-varying country attributes the log of real per capital GDP, the log of real per capital health expenditure, the unemployment rate, and the fraction of the population residing in urban areas

Models were estimated by weighted least squares, weighting by the population of country c in year 


\section{National Cancer Institute}

U.S. National Institutes of Health

www.cancer.gov

NCITerm Browser

EVS Enterprise Vocabulary Services

\section{Terminologies Value Sets Mappings}

Version: 12.10e (Release date: 2012-10-31-08:00)

$$
\begin{aligned}
& \text { myeloma } \\
& \text { Exact Match } \odot \text { Begins With } \odot \text { Contains } \\
& - \text { Name/Code } \odot \text { Property } \odot \text { Relationship }
\end{aligned}
$$

Advanced Search

$\underline{\text { Hierarchy I Value Sets I Maps I Visited Concepts }}$

Help

Quick Links

View in Hierarchy I View History I Add to Cart I Suggest Changes

\section{Chemotherapy Regimen Used to Treat Plasma Cell Myeloma (Code C63496)}

\section{Synomym Details Relationships \\ Mappings \\ View All \\ Relationships with other $\mathrm{NCl}$ Thesaurus Concepts}

Parent Concepts: Chemotherapy Regimen

Child Concepts:

Bortezomib-Dexamethasone Regimen

Cyclophosphamide-VAD Regimen

DT-PACE Regimen

DVD Regimen

Lenalidomide-Dexamethasone Regimen

MP-Myeloma Regimen

MPB Regimen

MPT Regimen

Thalidomide-Dexamethasone Regimen

VAD Regimen

VBMCP Regimen

VMCP-VBAP Regimen

Role Relationships: (none)

Associations: (none)

Inverse Role Relationships: (none)

Inverse Associations: (none)

Mapping relationships:

see Mappings

$\underline{\mathrm{NCl} \text { Home }}$ | $\underline{\text { Contact Us }}$ | Policies | Accessibility | FOIA

A Service of the National Cancer Institute

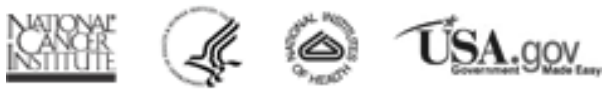




\title{
Appendix 2
}

\author{
OncologyStat ${ }^{\circledR}$ One Source, Many Resources. ${ }^{\circledR}$ By Elsevier
}

\section{CHEMOTHERAPY REGIMENS}

Completely revised and updated, The Elsevier Guide to Oncology Drugs and Regimens (2012 edition) provides more than 290 drug regimens commonly used in the treatment of 26 cancer types. Browse our comprehensive list by cancer type or drug name.

Recommended supportive therapy for the adverse effects most commonly associated with each regimen is also included.

Copyright and disclaimer

\section{Results for Multiple Myeloma}

\section{Bortezomib}

The Elsevier Guide to Oncology Drugs \& Regimens (2012 edition)

This Regimen Is Used for:Maintenance therapy Salvage therapy Regimen Details Bortezomib 1.3 mg/m2 I.V. on days 1, 4, 8 , and 11 Repeat every 21 days for up to eight cycles. Followed by Bortezomib $1.3 \mathrm{mg} / \mathrm{m} 2 \ldots$

\section{Bortezomib, liposomal doxorubicin}

The Elsevier Guide to Oncology Drugs \& Regimens (2012 edition)

This Regimen Is Used for:Salvage therapy Regimen Details Bortezomib $1.3 \mathrm{mg} / \mathrm{m} 2$ I.V. bolus on days 1, 4, 8, and 11 Liposomal doxorubicin $30 \mathrm{mg} / \mathrm{m} 2$ I.V. over 1 hour on day 4 following bortezomib administration Repeat...

\section{DVd (pegylated liposomal doxorubicin, vincristine, dexamethasone)}

The Elsevier Guide to Oncology Drugs \& Regimens (2012 edition)

This Regimen Is Used for:Primary induction therapy Regimen Details Pegylated liposomal doxorubicin $40 \mathrm{mg} / \mathrm{m} 2 \mathrm{I} . \mathrm{V}$. on day 1 Vincristine $1.4 \mathrm{mg} / \mathrm{m} 2$ (maximum, $2 \mathrm{mg}$ ) I.V. on day 1 Dexamethasone $40 \mathrm{mg}$ P.O. or...

\section{DVd-T (pegylated liposomal doxorubicin, vincristine, dexamethasone, thalidomide)}

The Elsevier Guide to Oncology Drugs \& Regimens (2012 edition)

This Regimen Is Used for:Non-transplant candidate therapy Regimen Details Pegylated liposomal doxorubicin $40 \mathrm{mg} / \mathrm{m} 2 \mathrm{I} . \mathrm{V}$. over 2 to 3 hours on day 1 Vincristine $1.4 \mathrm{mg} / \mathrm{m} 2$ (maximum, $2 \mathrm{mg}$ ) I.V. on day 1 Dexamethasone...

\section{Lenalidomide, dexamethasone}

The Elsevier Guide to Oncology Drugs \& Regimens (2012 edition)

This Regimen Is Used for:Primary therapy, transplant candidates Primary therapy, non-transplant candidates Salvage therapy Biomarker Testing:Chromosome del(5q) Regimen Details Lenalidomide 25 mg P.O. daily...

\section{MP (melphalan, prednisone)}

The Elsevier Guide to Oncology Drugs \& Regimens (2012 edition)

This Regimen Is Used for:Non-transplant candidate therapy Regimen Details Melphalan $8 \mathrm{mg} / \mathrm{m} 2$ P.O. on days 1 through 4 Prednisone $60 \mathrm{mg} / \mathrm{m} 2$ P.O. on days 1 through 4 Repeat cycle every 4 weeks. Or Melphalan...

\section{Melphalan, prednisone, thalidomide (MPT)}

The Elsevier Guide to Oncology Drugs \& Regimens (2012 edition)

This Regimen Is Used for:Primary induction therapy Primary non-transplant candidate therapy Regimen Details Melphalan 4 mg/m2 P.O. on days 1 through 7 Prednisone $40 \mathrm{mg} / \mathrm{m} 2$ P.O. on days 1 through 7 Thalidomide...

\section{Thalidomide}

The Elsevier Guide to Oncology Drugs \& Regimens (2012 edition)

This Regimen Is Used for:Maintenance therapy only Regimen Details Thalidomide 200 to 800 mg P.O. daily at bedtime References: Attal M, Harousseau J-L, Leyvraz S, et al. Maintenance therapy with thalidomide...

\section{Thalidomide, dexamethasone}

The Elsevier Guide to Oncology Drugs \& Regimens (2012 edition)

This Regimen Is Used for:Primary induction therapy in both transplant-eligible and non-transplant-eligible patients Regimen Details Thalidomide 100 to $200 \mathrm{mg}$ P.O. daily at bedtime for 2 weeks; then increase...

\section{VAD (vincristine, doxorubicin [Adriamycin], dexamethasone)}

The Elsevier Guide to Oncology Drugs \& Regimens (2012 edition)

This Regimen Is Used for:Primary induction therapy in non-transplant candidates Regimen Details Vincristine 0.4 mg daily by continuous I.V. infusion on days 1 through 4 Doxorubicin $9 \mathrm{mg} / \mathrm{m} 2$ daily by continuous... 